\title{
Why open surgery \\ for treatment of paediatric varicocele?
}

\author{
Perchè la chirurgia aperta nel trattamento del varicocele in età pediatrica?
}

G. Bolla ${ }^{1}$

Key words: Paediatric Varicocele - Surgical Ligature - Antegrade Sclerotherapy

\begin{abstract}
The high surgical ligature of spermatic vessels modified Palomo and the antegrade sclerotherapy according to Tauber represent two therapeutic modalities at last assured. In the experience of the Author the surgical technique is better with regard to the appearance of relapsing varicocele and the mean operative time.
\end{abstract}

\section{Riassunto}

La legatura alta dei vasi spermatici secondo Palomo e la scleroterapia anterograda secondo Tauber rappresentano due modalità di terapia del varicocele ormai verificate. Nell'esperienza dell'Autore la tecnica chirurgica si è rivelata migliore per quanto riguarda una eventuale recidiva del varicocele e per ciò che attiene ai tempi operatori.

\section{Introduction}

Varicocele is a physical abnormality present in $11 \%$ of adult males ${ }^{1,2}$ and in $25 \%$ of those with abnormal semen analysis. ${ }^{3}$ Therapeutic approach for adolescent varicocele remains admitting of several treatments, comparable with regard to safety and efficacy. ${ }^{4}$ The results in two different patterns of treatment of paediatric varicocele were evaluated in this study: the varicocelectomy modified Palomo ${ }^{5}$ versus antegrade sclerotherapy according to Tauber. ${ }^{6}$ We would have compare the safety and the efficacy of two modalities of treatment, particularly about the relapse of the varicocele.

\footnotetext{
Department of Pediatric Urology- O.C. Dolo (Venice - Italy)

Indirizzo per la corrispondenza (Corresponding author): Bolla Giorgio MD - Via Comino 52 - 35126 - Padova giorgio.bolla@libero.it
}

\section{Methods}

From June 2007 to May 2013 one hundred boys suffering for left idiopathic varicocele (second-third degree) were included in our therapeutic study: the diagnosis of varicocele was made by clinical examination and was confirmed by Color Doppler analysis; 50 boys were treated by surgical ligature of spermatic vessels through an access just above the inguinal channel and as many by antegrade sclerotherapy performed with an injection into a vein of the spermatic cord at the apex of the scrotum - after the phlebography - of 1\% Lauromacrogol $4 \mathrm{ml}$. (mean age 12,3 years and 13,3 years). We obtained the informed consent from the parents and the ethics approval according to Helsinki Declaration. The selection of patients has been made with random pattern; afterwards, the previous clinical outcome (absence of relapse for the boys who have undergone the operation) allowed us to prefer the surgical therapy for the boys with testicular hypotrophy. All the boys were subjected to spinal anaesthesia. Twelve boys of first group demonstrated testicular hypotrophy, eight of second group. The mean operative time was for the first group, for the second; mean follow-up was 22,18 m. and 19,14 m. respectively. The follow-up was carried out 3 and 12 months after treatment. The statistical analysis about the incidence of relapse of varicocele after the treatment has been performed by the Wilcoxon Test for independent samples ( $\left.\mathrm{N}^{1} 50-\mathrm{N}^{2} 50\right)$.

\section{Results}

In the first group (Palomo) we didn't find relapses of the varicocele. The group treated by sclerotherapy showed an incidence of relapse of varicocele: 6\% (all the relapses were noticed at first control: this aspect seems to be an unsuccessful recovery since the beginning and therefore a possible consequence of the inadequacy of the technique ). Three boys treated by surgical ligature have 


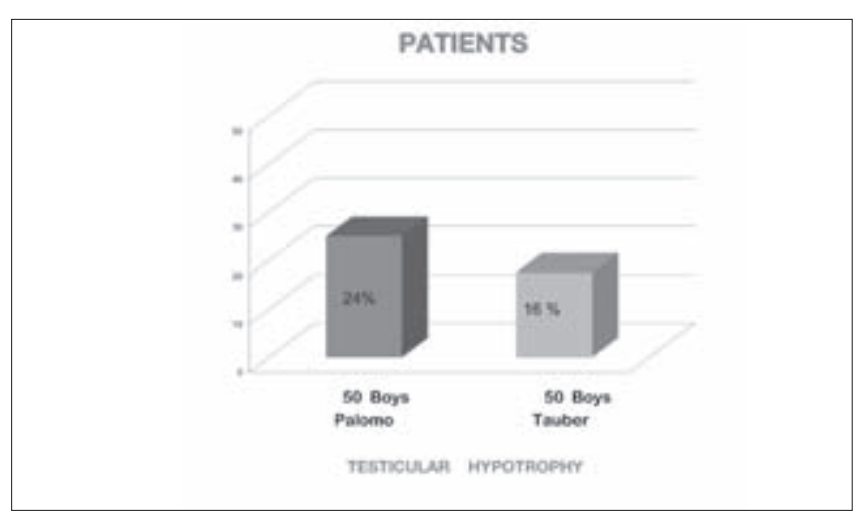

The incidence of testicular hypotrophy

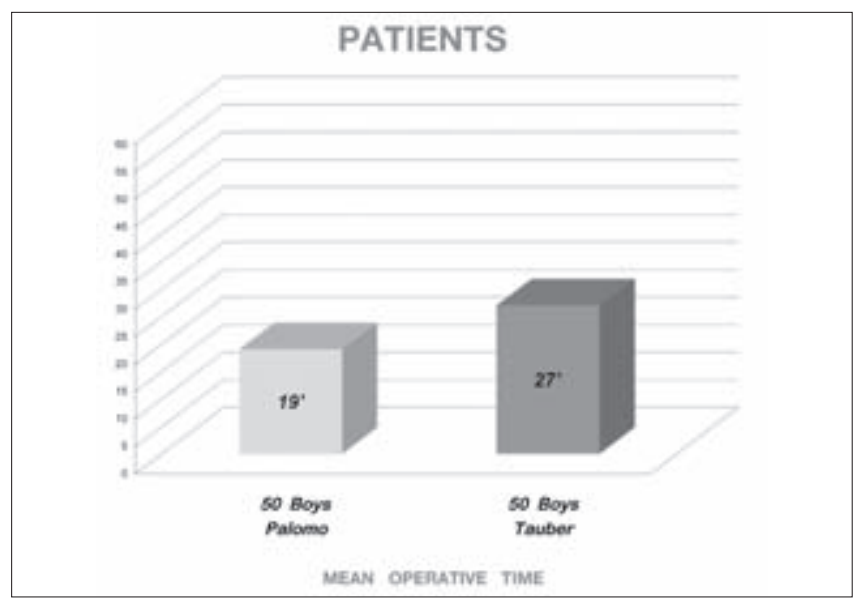

Mean operative time

Figure 2.

produced a left hydrocele and three boys treated by sclerotherapy showed a modest haematoma into the spermatic cord.

\section{Discussion}

There is a clear variability on treatment of pediatric varicocele, till now. ${ }^{7,8}$ This aspect is an indication of uncertainty about the therapeutical approaches to the problem. The variability regards either the surgical treatments (like the ligature of the vessels or the veins on a different level and like the various vascular anastomoses) or the other therapies (antegrade or retrograde sclerotherapy, retrograde embolisation). ${ }^{9,10}$ In our opinion the treatment of paediatric varicocele ought to do at diagnosis, with the intention to prevent a possible future infertility. ${ }^{11,12}$ Unavoidably for the adolescents the functional valuation of the fertility is not possible, for ethical reasons and hormone release. The clinical samples, in our experience, were too little for a statistical significance, but the trend about the incidence of relapse has been definite. For paediatric age we believe the spinal anaesthesia more effective in the sclerotherapy too: the boy gets an excellent analgesia without the need of a contemporary leptoanalgesia while in case of a local anaesthesia the injection of the anaesthetic drug into the spermatic cord (immediately before the sclerotherapy) can be troublesome. The antegrade sclerotherapy showed an appearance of relapse, although restricted. Lastly, the laparoscopic approach requests a triple access, a general anaesthesia and it involves a longer operative time than the open surgery. ${ }^{13}$

\section{Conclusion}

The surgical open ligature shows itself, by these preliminary compared data, as a method of treatment very efficacious, ${ }^{14,15}$ with a short operative time and without evident complications.

\section{References}

1 Pfeiffer D, Berger J. Schoop C, et al. A Doppler-based study on the prevalence of varicocele in German children and adolescents. Andrologia 2006;38(1):13-19.

2 Hargreave TB. Varicocele. Male Infertility, Berlin:Springer-Verlag 1994.

3 Nieschlag E, Hertle L, Fischedick A, et al. Treatment of varicocele: counselling as effective as occlusion of the vena spermatica. Hum Reprod 1995;10(2):347-353.

4 Riccabona M, Oswald J, Koen M, et al. Optimizing the operative treatment of boys with varicocele:sequential comparison of 4 techniques. J Urol 2003;169(2):666-668.

5 Palomo A. Radical cure of varicocele by a new technique; preliminary report. J Urol 1949; 61:604-607.

6 Tauber R, Johnsen N. Antegrade scrotal sclerotherapy for the treatment of varicocele:technique and late results. J Urol 1994;151:386.

7 Boman JM, Libman J, Zini A. Microsurgical varicocelectomy for isolated asthenospermia. J Urol 2008;180(5):2129-2132.

8 Kogan SJ. The Pediatric Varicocele. Saunders, Eds. Pediatric Urology 2001:763-773.

9 Feber KM, Kass EJ. Varicocelectomy in adolescent boys: long-term experience with the Palomo procedure. J Urol 2008;180(4 Suppl.):1657-1659.

10 Evers JL, Collins JA. Surgery or embolisation for varicocele in subfertile men. Cochrane Database Syst Rev 2004;3:CD000479.

11 Laven JS, Haans LC, Mali WP, et al. Effects of varicocele treatment in adolescents: a randomized study. Fertil Steril 1992;58(4):756-762.

12 Butler GE, Ratcliffe SG. Serono Symposia Rewiews. 1984;Suppl. 1:244.

13 Miersch WD, Schoeneich G, Winter P, et al. Laparoscopic varicocelectomy: indication, technique and surgical results. Br J Urol 1995;76(5):636638.

14 Bolla G, Sartore G. Comparison of surgery with sclerotherapy for treatment of paediatric varicocele. Book of the first global Congress for Consensus in Pediatrics and Child Health, Paris 2011: 161.

15 Okuyama A. Surgical repair of varicocele at puberty: preventive treatment for fertility improvement. J Urol 1988;139:562-564. 